\title{
Spinocerebellar Ataxia
}

National Cancer Institute

\section{Source}

National Cancer Institute. Spinocerebellar Ataxia. NCI Thesaurus. Code C82341.

An inherited disorder characterized by degeneration of the spinal cord and the cerebellum. Symptoms may appear at any age and include progressive loss of coordination of gait, hands, speech, and eye movements. 